\title{
COMPLEMENTOS VERBALES DE MEDIDA NO PREPOSICIONALES EN ESPAÑOL
}

\author{
P. Pablo Devís Márquez \\ Universidad de Cádiz
}

\section{RESUMEN}

El propósito general de este artículo es el estudio de los complementos verbales de medida no preposicionales en la lengua española. Objetivos particulares de nuestro trabajo son los siguientes:

1) Analizar los problemas que supone asignar una función sintáctica a estos complementos.

2) Probar que la negación de la clitización de estos complementos en todos los casos parte de un concepto problemático de referencia y de una descripción parcial de la realidad del español.

3) Postular la naturaleza denotativa de los sustantivos núcleos de estos complementos, la incompatibilidad entre la expresión de la medida y la discriminación denotativa individualizadora, y la compatibilidad entre la expresión de la medida y la discriminación deíctica en el caso de estos complementos.

4) Sugerir la necesidad de distinguir la modificación referencial de los sustantivos de medida de la de los SSNN de medida completos y la posibilidad de que la primera, frente a lo sostenido por otros, pueda ser llevada a cabo por medio de la complementación nominal, que nunca será restrictiva o explicativa, sino de lo que hemos denominado «especialización denotativa».

5) Clasificar los tipos de estructuras y de verbos que aparecen con estos complementos en español.

Nuestro punto de vista será exclusivamente sincrónico.

Palabras clave: Complemento verbal de medida no preposicional; función sintáctica; clitización; referencia; modificación referencial.

\section{Abstract}

The general purpose of this article is the study of non prepositional measure verb complements in Spanish. Particular aims are the following:

1) To analyse the problems when these complements are assigned a syntactic function.

2) To prove that denying the cliticization of these complements stems from a problematical concept of reference and from a misrepresentation of the Spanish facts.

3) To postulate the denotative nature of the nouns heading these complements, the incompatibility between expressing measure and the individualizing denotative discrimination, and the compatibility between expressing measure and deictic discrimination in the case of these complements. 
4) To suggest the need to distinguish the referential modification of measure nouns from that of measure noun phrases, and the possibility that, contrary to what has been held elsewhere, the former can be carried out by means of the noun complementation, which will never be restrictive or explanatory, but specializing.

5) To classify the types of syntactic structures and verbs taking these complements in Spanish.

Our point of view is exclusively synchronic.

Key Words: Non prepositional measure verb complement; syntactic function; reference; referential modification.

\section{INTRODUCGIón}

Las secuencias no introducidas por preposición que en español expresan medida pueden ser tanto complemento del verbo (mide dos metros, trabajó dos horas) o su sujeto (en este recipiente caben dos litros), como modificadores de otro tipo de unidades lingüísticas. En este último caso no sólo nos topamos con construcciones de tipo comparativo - (es) dos centimetros más corto-, sino también, aunque con mucha menor frecuencia, con otras que carecen de esta propiedad (llegó dos horas tarde; fue cinco veces tonto; recorrió dos veces esa distancia) ${ }^{1}$.

El propósito general de este artículo es el estudio de los complementos verbales de medida no preposicionales en la lengua española. Habrá que advertir, no obstante, que la expresión de la medida no es una característica intrínseca de estas secuencias. Un mismo grupo de palabras expresará medida o no, dependiendo del verbo al que acompañe. Así, dos horas mide la duración temporal de la película en la película duró dos horas, pero no expresa medición de magnitud alguna en los concursantes necesitaron dos horas o en dos horas pasan rápidamente, sino una cantidad meramente numerable. Por otra parte, estos complementos pueden acompañar tanto a verbos cuyo significado léxico exige la expresión de

\footnotetext{
${ }^{1}$ Construcciones como fue cinco veces tonto y recorrió dos veces esa distancia no dejan de ser ambiguas. Cinco veces y dos veces pueden referirse al número de veces que alguien fue tonto y al número de veces que alguien recorrió una distancia, respectivamente, y entonces serían complementos verbales, o pueden hacerlo a la intensidad con la que alguien fue tonto y al doble de esa distancia, respectivamente, con lo que estaríamos ante un cuantificador del adjetivo (tonto) $\mathrm{y}$ ante otro de un sustantivo (distancia).

Brucart 2001, pp. 44-48, alude a cómo los adjetivos en español, frente a lo que ocurre en otras lenguas (the man was two meters tall; l'uomo era alto due metri; der Mann war zwei Meter gro $\beta$ ), no aceptan ser modificados directamente por lo que denomina sintagmas nominales de medida (*un edificio \{veinte metros/cuatro veces\} alto). La razón de esto la atribuye este autor a que los adjetivos españoles carecen del rasgo léxico [+vectorial], es decir, a que no llevan implícito un punto de origen determinado a partir del cual pueda aplicarse el sintagma de medida. No obstante, advierte la existencia de lo que considera excepciones (la falda le quedaba cinco centímetros corta) en las que, curiosamente, el origen no puede expresarse explícitamente (*la falda le quedaba cinco centímetros corta de lo conveniente).
} 
la medida de una magnitud (duró dos horas) como a verbos cuyo significado léxico no la exige (trabajó dos horas; estuvo quejándose dos horas)².

Objetivos particulares de nuestro trabajo son los siguientes: 1) analizar los problemas que supone asignar una función sintáctica a estos complementos $(\S 2) ; 2$ ) probar que la negación de la clitización de estos complementos en todos los casos parte de un concepto problemático de referencia y de una descripción parcial de la realidad del español (§3); 3) postular la naturaleza denotativa de los sustantivos núcleos de estos complementos -habitualmente negada por muchos-, la incompatibilidad entre la expresión de la medida y la discriminación denotativa individualizadora, y la compatibilidad entre la expresión de la medida y la discriminación deíctica en el caso de estos complementos (§4);4) sugerir la necesidad de distinguir la modificación referencial de los sustantivos de medida de la de los SSNN de medida completos y la posibilidad de que la primera, frente a lo sostenido por otros, pueda ser llevada a cabo por medio de la complementación nominal, que nunca será restrictiva o explicativa, sino de lo que hemos denominado «especialización denotativa» (\$5), y 5) clasificar los tipos de estructuras y de verbos que aparecen con estos complementos en español (\$6). Nuestro punto de vista será exclusivamente sincrónico.

\section{LA FUNCIÓN SINTÁCTICA DE LOS COMPLEMENTOS DE MEDIDA}

La gramática española, en un principio, parte de la idea de que los complementos verbales que expresan medida, debido, sobre todo, a su valor cuantitativo e independientemente del verbo a que acompañen, son complementos circunstanciales. No obstante, en el caso de aquellos no introducidos por preposición, aun sin renunciar a su carácter circunstancial y debido a sus orígenes latinos, se establece cierta relación con lo que se denomina acusativo o complemento directo (cf. RAE 1931, pp. 203, 1983, p. 376 y Roca Pons 1980, p. 290). Esto desata una de las cuestiones que mayor debate ha suscitado con este tipo de complementos verbales cuando se encuentran junto a verbos cuyo significado léxico implica la expresión de la medida: la de su función sintáctica.

Las propuestas que en este sentido se han ofrecido no han dejado de producir resultados desde nuestro punto de vista absolutamente estériles en una adecuada descripción de las relaciones y funciones sintácticas que en casos como éstos presenta la lengua española. Así, en tanto que algunos autores, aun advirtiendo la sustitución pronominal en acusativo

\footnotetext{
${ }^{2}$ Lo mismo sucede cuando van introducidos por preposición, casos que algunos autores (cf. Bosque 1998, p. 59) no han catalogado como auténticos complementos verbales, sino de la preposición (la factura asciende a cien euros; trabajó durante dos horas). Acerca de la consideración de los sintagmas preposicionales como construcciones endocéntricas cuyo núcleo es la preposición y posibles dificultades, cf. Devís Márquez 2004, pp. 125-126.
} 
de muchos de estos complementos, hacen prevalecer su carácter cuantitativo para seguir considerándolos circunstanciales (cf. Porto Dapena 1993 , p. 48), otros muchos, precisa y fundamentalmente por ese tipo de pronominalización, se decantan por la función de objeto directo. Entre estos últimos destacan varios: Alcina Franch y Blecua 1975, p. 897; Cano Aguilar 1981, pp. 320-322, quien en el caso de lo que llama complementos de medida con verbos como pesar o medir (pesa ochenta kilos; esa tela mide dos metros) y en el de los que denomina complementos de extensión temporal o espacial (andar dos millas; la conferencia duró dos horas), que, obviamente, pensamos, no dejan de medir igualmente magnitudes, no sólo señala la pronominalización (los pesa; esa tela los mide), sino también la admisión de formas pasivas (los diez kilos pesados por el paquete; los dos metros medidos por la tela) como pruebas de su propuesta ${ }^{3}$; Pérez 1989, pp. 476-477, que se refiere a los verbos que expresan medida, duración, peso, precio...; Alarcos Llorach 1994, pp. 281-282, quien añade la prueba de que estos complementos pueden ser reproducidos por el interrogativo qué (¿qué medía la torre?) y todo ello aun cuando es el propio Alarcos el que admite que estos adyacentes igualmente pueden ser reproducidos por cuánto, que él considera un adverbio (¿cuánto media?), y otros cuantificadores adverbiales (medía mucho/bastante/demasiado/poco) ${ }^{4}$; Fernández Lagunilla y Anula Rebollo 1995, pp. 285-286, quienes, a pesar de negar la existencia de una prueba rigurosa identificadora del objeto directo, hablan de objetos directos de medida con carácter nominal, que admiten la pronominalización (María midió dos metros; María los midió), y con carácter adverbial, que no la admiten (María midió mucho; *María lo midió); Espinosa García 1995-1996, p. 318, 1997, pp. 175, n. 111, y 415 y ss., y 1998, p. 281, n. 7, que, además, advierte en estos casos una cuantificación que afecta, no al ámbito del SN, sino al de toda la oración; Marcos Marín, Satorre Grau y Viejo Sánchez 1998, pp. 333-334, que, como dato complementario, insisten en el carácter de complementos regidos por determinados verbos de estas secuencias, pues no es posible su elisión (*el campo

\footnotetext{
${ }^{3}$ Aparte de la dudosa aceptabilidad de ejemplos como los dos últimos, no parece posible admitirlos como paráfrasis de el paquete pesa diez kilos y la tela mide dos metros, respectivamente, desde el momento en que en los primeros el artículo determinado introduce las secuencias que expresan medida, pero no en los segundos. Lo que sí resulta evidente es la imposibilidad de que estos complementos de medida se conviertan en sujetos de estructuras con auxiliar + participio en español, vayan introducidos por el artículo o no -*(los) diez kilos son pesados por el paquete; *(los) dos metros son medidos por la tela-. No obstante, esto no supondría dificultad alguna en su catalogación como objetos directos. En nuestra lengua, si bien sólo los complementos con pronominalización acusativa pueden pasar a sujeto en la pasiva correspondiente, no todo complemento con este tipo de pronominalización goza de esta capacidad (* los niños son tenidos en casa por Juan). Ello despoja de un carácter decisivo a la prueba de la construcción pasiva en la identificación del objeto directo en español.

${ }^{4} \mathrm{Si}$ bien es cierto que las cuantificaciones que tradicionalmente se han considerado circunstanciales no responden nunca a ¿qqué? (¿qué estudiaste?: *dos horas), también lo es que otras secuencias a las que se suele asignar una función sintáctica distinta de la de objeto directo sí lo hacen (¿qué destrozó la valla?: un camión).
} 
mide; *la película dura; *el saco pesa; *el libro vale) $)^{5}$; Báez San José 2002, p. 310 , que alude a la pronominalización cuando emplea la marca \pm cuantitativo en la caracterización de lo que denomina objeto directo; Cuartero Otal 2003, p. 80, etc. Argumentos en contra de la interpretación de estos complementos como objetos directos ofrece, por ejemplo, Goldin 1968, p. 26, quien, a partir de la idea de que en español ejemplos como la pintura vale mil pesos o yo peso sesenta kilos sólo admiten la pronominalización con el pronombre no marcado lo (la pintura lo vale; yo lo peso, obviándose opciones gramaticales como la pintura los vale; yo los peso), señala que nos encontramos ante un caso profundo de medida que no está afectado por las reglas que seleccionan sujetos pasivos y objetos directos activos, si bien no se refiere a caracterización sintáctica alguna. Sánchez López 1999, p. 1121, admite la pronominalización acusativa con estos complementos, pero alude a una mayor aceptabilidad de ésta cuando el contexto ha introducido previamente la cantidad (tres horas, la operación las duró sobradamente) y, más que con su consideración como objetos directos, la relaciona con una interpretación definida de los complementos de medida $^{6}$. Bosque 1989, pp. 81 y 206, por su parte, distingue entre ssnn que contienen una cuantificación argumental, a los que considera objetos directos (duró dos horas), y sSNN del mismo tipo no argumentales, a los que cataloga como complementos circunstanciales (durmió dos horas).

Otra propuesta menos extendida parte de la consideración de estos complementos verbales como complementos adverbiales. La idea se encuentra en Rojo 1985, pp. 188-190, y 1990, p. 168, para quien los complementos que él llama de medida, duración, peso y precio no introducidos por preposición, aun a pesar de su pronominalización acusativa y debido a su carácter argumental, a su imposibilidad de ser sujetos de construcciones pasivas y a la posibilidad de ser sustituidos por lo que se considera un adverbio de cantidad, no son ni circunstanciales o aditamentos, ni objetos directos, sino representantes de una función sintáctica distinta denominada complemento adverbial (mide cinco metros; los mide; mide mucho). Con este autor se muestra de acuerdo Álvarez Martínez 1987, p. 55. Ahora bien, el carácter argumental de estos denominados complementos adverbiales jamás podría ser justificado por ninguna de las pruebas propuestas por Rojo, pues, al tratarse de construcciones que carecen de valor activo, al menos en los ejemplos que se proponen, ninguna de ellas

\footnotetext{
${ }^{5}$ La discusión acerca de los problemas de la elisión como criterio para establecer la argumentalidad ya fue iniciada en el ámbito de nuestra tradición gramatical por Rojo 1985. La agramaticalidad de ejemplos como la película dura o el saco pesa no deja de ser, cuanto menos, dudosa.

${ }^{6}$ Sánchez López ob. cit., p. 1116, siguiendo una amplia tradición a la que luego haremos alusión, plantea que los complementos verbales de medida denotan cantidades y que, por lo tanto, carecen de valor referencial. Sólo admite SSNN definidos en estos casos si denotan cantidad de forma deíctica (discursiva o pragmáticamente). No obstante, esta autora ob. cit., p. 1115, piensa que los complementos de medida representan verdaderos argumentos seleccionados por el verbo, pues su ausencia haría agramatical una oración.
} 
podría ser parafraseada por la proforma hacerlo a la manera de Happ 1978. Igualmente, la elisión de estos complementos de medida no siempre parece imposible en español (cf. n. 5). Con respecto a la imposibilidad de la llamada construcción pasiva, ya hemos aludido al carácter no decisivo de este dato en la catalogación de un complemento verbal como objeto directo en español (cf. n. 3). Tampoco parece acertada la idea de que los llamados complementos adverbiales pueden ser sustituidos por adverbios de cantidad en tanto que los verdaderos objetos directos no pueden. Si ante ejemplos como leyeron esas novelas y leyeron mucho postula Rojo que una y otra son estructuras diferentes -en tanto que la primera admite la pronominalización (leyeron esas novelas/las leyeron), esto no sucede con la segunda (leyeron mucho), en la que lo no podría sustituir a mucho-, lo mismo habría que decir, tal y como advirtieron Pérez 1989, p. 476, n. 13, y Espinosa García 1995-1996, p. 320, y 1998, p. 276, ante casos como pesa ochenta kilos/pesa mucho. Por nuestra parte, añadimos que parece un tanto contradictorio que ante un ejemplo como leyeron mucho no se considere mucho objeto directo únicamente por no responder a la pronominalización y que sea el propio Rojo 1985, p. 188, el que, para rechazar la función de objeto directo en lo que él llama complementos adverbiales que expresan medida, que sí admiten la pronominalización acusativa, proponga no otorgar un valor decisivo a esta pronominalización. Es más, incluso, aunque sin ejemplos, señala la existencia de objetos directos sin pronominalización acusativa y de no objetos directos con ella. Además, tanto Pérez, ob. cit., p. 476, como Espinosa García 1995-1996, pp. 319 y 320, n. 12, y 1998, p. 277, han dudado del carácter adverbial de unidades como mucho, poco, bastante, demasiado, etc. Para la primera estamos ante pronombres indefinidos, para el segundo ante prosintagmas ${ }^{7}$. Sin entrar ahora en discusiones acerca de la asignación de una u otra categoría verbal o sobre a qué sustituyen en concreto las unidades citadas, partimos de la idea de Cuartero Otal, ob. cit., p. 80, de que mucho, como poco, demasiado, etc., son comodines semánticos referidos a cualquier tipo de cuantificación, para, desde nuestro punto de vista, concluir que, desde el momento en que estas unidades sirven para expresar tanto la medida de una cantidad mensurable como la cantidad meramente numerable, resulta evidente que pueden acompañar no sólo a verbos que exigen la expresión de la medida (duró mucho), sino también a los que no lo hacen (comió mucho) y que, por tanto, no son útiles a la hora de distinguir el régimen de unos y otros.

Por último, Demonte y Masullo 1999, pp. 2517-2518, proponen que los complementos no introducidos por preposición que acompañan a verbos que expresan medida son complementos predicativos. No nega-

\footnotetext{
${ }^{7}$ La idea la aplica también Gutiérrez Ordóñez 1997, pp. 187 y 192, aunque sólo a los complementos temporales y locativos. Así, desde el momento que identifica los tradicionales adverbios de lugar y tiempo como proformas nominales, advierte lo innecesario de la distinción entre suplementos y complementos adverbiales.
} 
mos que muchos de estos complementos atribuyen, como dicen estos autores, una propiedad (su altura, peso, etc.) al denominado sujeto de la oración, pero resulta evidente que otros tantos no lo hacen. Así, si bien en Juan pesa setenta kilos, setenta kilos mide el peso de Juan, en Juan tardó dos horas, dos horas no mide el tiempo de Juan, sino el de la tardanza. Además, resulta difícil aceptar cualquiera de las tres pruebas que ofrecen acerca del carácter predicativo y no argumental de este tipo de complementos: 1) independientemente de que no parezca cierta la imposibilidad de que vayan introducidos por determinantes definidos (mide los dos metros), el hecho de que sí lo fuera no podría emplearse como indicio para catalogar un complemento ni como predicativo ni como no argumental, pues tanto predicativos y no predicativos como argumentales y no argumentales gozan de la posibilidad de ir introducidos o no por determinantes definidos (considero a tu hermano inteligente; considero a tu hermano el hombre más inteligente de la Tierra) ${ }^{8}$; 2) la imposibilidad de pasivización, ya lo hemos advertido, se encuentra también en estructuras con complementos que no son predicativos, y 3) Demonte y Masullo proponen como prueba del carácter predicativo y no argumental de los complementos de medida a los que nos referimos el hecho de que las estructuras en las que aparecen pueden ser parafraseadas por otras con el verbo ser en las que la expresión de la medida debe ir necesariamente introducida por la preposición soporte $d e$, la cual, dicen, se especializa en convertir SSNN en expresiones atributivas (la reunión duró dos horas = la reunión fue de dos horas). Desde nuestro punto de vista, las relaciones parafrásticas sólo muestran identidades designativas, pero no lingüísticas. Aceptar la propuesta de Demonte y Masullo sería como asumir, por ejemplo, que la nariz en golpeó la nariz a Juan es un circunstancial locativo por el hecho de que esa construcción puede ser parafraseada por golpeó a Juan en la nariz o que en esta última en la nariz es un objeto directo por su relación parafrástica con la primera. Por otra parte, ni siempre la preposición de tiene la capacidad de convertir SSNN en expresiones atributivas (viene de Cádiz), ni es ésta la única con esta capacidad (hombre sin brazo), ni todas las estructuras con verbos que exigen la expresión de la medida permiten la paráfrasis citada (Juan tardó dos horas; *Juan fue de dos horas, aunque sí la tardanza fue de dos horas). Tampoco los otros tipos de complementos predicativos. Piénsese, por ejemplo, en considero inteligente a Juan .

\footnotetext{
${ }^{8}$ Son los propios Demonte y Masullo ob. cit., p. 2472, los que reconocen que hay predicativos con nombres precedidos de determinantes definidos (considero a Beatriz la mejor alcaldesa), pero, dicen, se trata de expresiones no referenciales: la mejor alcaldesa es un predicado de singularidad o exclusividad, ya que, señalan, la presencia de mejor convierte el nombre en un puro definidor de características en vez de ser la descripción de una persona, algo que no ocurriría, pensamos, en lo consideran el hombre que mató ayer a varios policías.

${ }^{9}$ La discusión acerca del estatus sintáctico de los complementos que estudiamos desborda las fronteras del español. Cf. Gràcia i Solé 1989, pp. 198-202, Ramos 1993, pp. 133-136, Smith 1992, Levin 1993, pp. 272-274, etc.
} 
En resumen, no parece que ninguno de los rasgos utilizados permita otorgar a los complementos de medida no preposicionales una función sintáctica concreta. Al contrario, muestran la gran diversidad que los caracteriza. La expresión de la cuantificación, si bien es una característica de este tipo de complementos, no es una propiedad privativa de ellos, sino que, al igual que el impedimento de ser sujeto de construcción pasiva o la sustitución por un adverbio de cantidad, la comparten otros constituyentes oracionales a los que suele otorgárseles funciones distintas (dos hombres caminaban; bebi cinco vasos de agua). La pronominalización acusativa, aun siendo posible con muchos de ellos, no es una característica compartida por todos los complementos de medida (tardó dos días; *los tardó). Lo mismo sucede con el rasgo «caracterizador del sujeto»y con la paráfrasis con $s e r+d e$. También con el carácter argumental, que, por otro lado, no es privativo. Además, esta clase de datos, de la que hablaremos en el apartado 6, aun siendo importante, todo lo más, sería útil para describir las secuencias que estudiamos a partir de ciertos tipos de comportamientos exclusivamente intralingüísticos, lo que no deja de ser pertinente en una gramática descriptiva, pero no para asignarles funciones sintácticas oracionales, sobre todo si por éstas entendemos universales del lenguaje que muestran el valor que adquieren los constituyentes oracionales como resultado de las relaciones sintagmáticas que mantienen con los demás constituyentes de su misma oración (cf. Devís Márquez 2000, pp. 140-146). Desde nuestro punto de vista, en lo que a la función sintáctica de estas secuencias que expresan medida se refiere, lo importante es, primero, distinguir las no regidas por el verbo de las que sí lo están y, después, advertir de que en tanto que en el ámbito de las primeras nos topamos con secuencias con la función de determinador de la relación ya establecida entre el denominado sujeto y el verbo (el cliente estuvo quejándose dos horas) o sólo del verbo (llovió dos horas), en el de las segundas no sólo existen las que ejercen la función de determinador (Juan mide dos metros; hay dos horas hasta Cádiz), sino también otras que, al tiempo que determinadoras, forman parte de lo determinado por otro complemento (pagó un euro por el lápiz) o cuya función es sólo la de determinado (dos litros caben/entran en este cubo), si bien estas últimas -tradicionales sujetos- no forman parte de nuestro objeto de estudio ${ }^{10}$.

\section{REFERENCIA, PRONOMINALIZACIÓN Y COMPLEMENTOS DE MEDIDA}

La pronominalización acusativa no sólo ha jugado un importante papel en el intento de asignar una función sintáctica a los complementos de medida, sino también a la hora de abordar el problema de su referencia.

\footnotetext{
${ }^{10}$ Acerca del orden de determinación de los constituyentes oracionales, cf. Devís Márquez 2005, pp. 367-371.
} 
La distinción de Chomsky 1982, p. 325, entre argumentos (elementos with potentially referential function que aluden a los participantes del suceso que se expresa) y cuasi-argumentos (elementos sin referencia que no aluden a participante alguno del suceso) identificó referencialidad con argumentalidad. Tal identificación es aceptada por Rizzi 1990, pp. 85-91 y 103, y Cinque 1990, p. 5, para quienes, en tanto que «agente», «tema», «meta», etc., son papeles referenciales y, por consiguiente, argumentales, «medida», «manera», etc., son papeles no referenciales y, por tanto, no argumentales. Al mismo tiempo, Cinque, ob. cit., pp. 8 y 16 , caracteriza la referencialidad como la capacidad de aludir a miembros específicos de un grupo o clase preestablecido ya en la mente del hablante, ya en el discurso. En este último caso, Cinque, ob. cit., p. 164, n. 17 , identifica la referencialidad con la noción de vinculación al discurso de Pesetsky 1987, pp. 107-108.

Que los clíticos se caractericen por poder sustituir a los argumentos llevó a que, de acuerdo con la identidad chomskyana entre referencialidad y argumentalidad, se haya dotado a aquéllos (los clíticos) de un estatus referencial. Esto, a su vez, condujo a que se haya negado la clitización de los SSNN de medida, a los que se había caracterizado como no referenciales. Así, Cinque, ob. cit., 104-105 y 162-163, n. 8, propone como agramatical en italiano que un hablante replique con *anch'io li peso a otro que afirma io peso 70 chili. Para él, los clíticos son compatibles con las frases de medida sólo cuando aquéllos se emplean, según este autor, no referencialmente ( 70 chili, non li pesa). Gràcia i Solé 1989, p. 197, duda de la gramaticalidad de construcciones catalanas como abans de pesar-los, en Pere volia pesar vuitanta quilos desde el momento en que, dice, sólo los SSNN referenciales pueden ser antecedentes de un pronombre al que no manda-como-constituyente. Bosque 1998, p. 57, n. 1 niega la posibilidad de que en español los SSNN de medida puedan ser sustituidos por el clítico acusativo (Juan tardó un día, *lo tardó), pues se trata de sintagmas cuantificativos inespecíficos -en lo que coinciden Demonte y Masullo, ob. cit., pp. 2517s. y, salvo en los casos de lo que llama una denotación deíctica de la cantidad (cf. n. 6), Sánchez López, ob. cit., 1116y tal clítico, advierte, no es sino un pronombre definido. Sólo admite la clitización en aquellas construcciones en las que, piensa, la propiedad se interpreta en sentido extremo como consecuencia de que se altera el valor del predicado. Para Bosque, en su hijo mide los dos metros (su hijo los mide), medir ha de interpretarse como alcanzar.

Desde nuestro punto de vista, la negación de la clitización de todos los SSNN de medida parte de un problemático concepto de referencia y, además, supone una descripción fallida de la realidad lingüística, al menos en español. La identificación arbitraria de la referencialidad con la argumentalidad dota de estatus referencial a los clíticos, es decir, los clíticos son referenciales porque sustituyen argumentos, mientras que 
la identificación, igualmente arbitraria, de la argumentalidad con determinados papeles $\theta$ impide caracterizar como referenciales los SSNN de medida, esto es, los SSNN de medida no son referenciales porque no son argumentales y, por consiguiente, no pueden ser sustituidos por clíticos. Del mismo modo, la identificación de la referencialidad con la definición-especificación dota de valor definido-específico a los clíticos. En este sentido, éstos no pueden sustituir sSNN no definidos-específicos, entre los que se encuentran los SSNN de medida. Todo ello impide aceptar lo que, al menos en español, resulta evidente: la clitización, si bien no de todos, sí de muchos de los SSNN de medida. Ejemplos como Gasol mide dos metros (los mide), la película duró dos horas (las duró), la casa cuesta dos millones (los cuesta) no son rechazados en la actualidad por los hablantes nativos de la lengua española (cf. Smith, ob. cit., pp. 309-310). Obviamente, nos topamos, pues, con complementos a los que habría que asignar un papel $\theta$ de los denominados no referenciales (medida) y, por consiguiente, no definido-específicos con la clitización típicamente argumental, algo que afecta seriamente a la identificación inicial de referencia con argumentalidad, de no referencia con no argumentalidad, de referencia con definición-especificación, de no referencia con no definición-especificación, y a la caracterización referencial y definidoespecífica de los clíticos. La asignación de un valor definido-específico a los clíticos como razón para negar la clitización de los SSNN de medida choca también con la posibilidad de encontrar construcciones con complementos a los que no habría más remedio que asignar un papel $\theta$ de los denominados referenciales y, por consiguiente, habría que catalogar como argumentos, que no hacen referencia a individuos u objetos específicos y que pueden ser sustituidos por clíticos o ser antecedentes de clíticos (busca criados; los busca; busca criados y los quiere para su casa de Madrid $)^{11}$.

\section{DENOTACIÓN, DisCRIMINACIÓN DENOTATIVA, DISGRIMINACIÓN DEÍCTI- CA Y COMPLEMENTOS DE MEDIDA}

Parece evidente, pues, que un concepto de referencia no tan restringido y arbitrario permitiría una mejor descripción del comportamiento de los complementos de medida.

Mendívil Giró 1994, pp. 101-102, partiendo de las ideas de Thrane, trata de romper con la noción de referencia identificada con la alusión a participantes individuales específicos del suceso que se relata ${ }^{12}$. Más que de referencia prefiere hablar de lo que denomina «independencia

\footnotetext{
${ }^{11}$ Ya Lyons 1981, p. 191, señaló las dificultades que entraña que un pronombre tenga un antecedente no referencial (no específico) a cualquier teoría de la pronominalización que se base en la noción de correferencia.

${ }^{12}$ Acerca de la relación entre referencia y la distinción específico/inespecífico, cf. Leonetti Jungl 1990, pp. 49-74.
} 
referencial» y considera que un constituyente es referencial por el mero hecho de ser un $\mathrm{SN}$, es decir, una proyección de $\mathrm{N}$, en el sentido de que está determinado de algún modo. Mendívil Giró, ob. cit., p. 104, establece una conexión directa entre determinación e independencia referencial, de modo que sólo se podrán considerar no referenciales aquellos SNs que no estén determinados (que no sean verdaderas proyecciones sintácticas) y que, por tanto, no puedan considerarse argumentos sintácticos. Ello llevaría a catalogar como referenciales (como independientes referencialmente) tanto SSNN específicos como no específicos y, por consiguiente, también los SSNN de medida. La pronominalización acusativa de éstos en muchos de los casos en que complementan al verbo dejaría de plantear problemas a la caracterización referencial de los clíticos.

Mendívil Giró alude a la determinación como un proceso de actualización (cita a Coseriu 1989 y a Bally 1965) que identifica con un proceso de acotación de la denotación léxica y, por ello, vincula la determinación con la referencialidad. No obstante, si atendemos en rigor al concepto de determinación tal y como lo presenta Coseriu, ob. cit., cabe decir que ni toda determinación es actualización, ni la actualización -al igual que sucede en Bally, ob. cit., pp. 77 y ss.- supone jamás acotación en la denotación de una unidad lingüística. Cuando Coseriu, ob. cit., pp. 291 y 304, habla de determinación se refiere a las operaciones que, en el lenguaje como actividad, sirven tanto para dirigir los signos lingüísticos hacia la realidad no lingüística (empírica o pensada), como para modificar sus posibilidades designativas. En el ámbito de lo primero, y sólo en referencia a la determinación nominal, incluye la actualización - entendida como una operación en la que un signo del sistema de la lengua (con designación virtual) es orientado hacia los objetos reales o pensados (designación real o denotación, cf. Coseriu, ob. cit., p. 294) ${ }^{13}$ y la discriminación -entendida como el conjunto de operaciones que orienta la denotación hacia un grupo eventual o real de entes particulares (cf. Coseriu, ob. cit., p. 297)-. En el ámbito de la modificación de las posibilidades designativas se encuentran la delimitación -que delimita la denotación, orientando la referencia hacia una parte o hacia un aspecto de lo denotado (cf. Coseriu, ob. cit., pp. 304-305) - y la identificación -que orienta al oyente hacia un valor semántico (cf. Coseriu, ob. cit., p. 306)-. Además, Mendívil Giró vincula la determinación con la referencia en tanto que concibe aquélla como un proceso de actualización o acotación en la denotación léxica del sustantivo, mientras que la determinación de la que habla finalmente no tiene que ver ni con una ni con otra, sino con la que se establece entre constituyentes oracionales.

\footnotetext{
${ }^{13}$ Para Bally la actualización también supone un paso de lo conceptual o virtual a lo real. Ahora bien, no alude a la actualización de signos, sino de conceptos y presenta el proceso como una identificación entre éstos y lo real: «Actualiser un concept, c'est l'identifier à une représentation réelle du sujet parlant» (cf. Bally, ob. cit., p. 77). Sin embargo, para Coseriu, ob. cit., p. 296, los conceptos son siempre virtuales y sólo pueden relacionarse, no identificarse, con lo real. Es precisamente esa relación lo que muestra la denotación.
} 
La referencialidad entendida como alusión a participantes individuales específicos del suceso relatado se identifica exclusivamente con un aspecto de la determinación en el sentido coseriuano, en concreto con parte de la discriminación. Ahora bien, si por referencia entendemos el ámbito de lo extralingüístico, no podemos limitar la capacidad que tienen las unidades lingüísticas de remitir a ese ámbito a sólo una de las maneras en las que esa remisión se lleva a cabo. Es preciso tener en cuenta los otros aspectos que Coseriu incluye en la determinación. Ello permitirá posicionarnos frente a los autores que identifican la referencialidad con la individualidad específica, los cuales advierten de la incompatibilidad de la expresión de la medida con el carácter referencial en un mismo sN. Desde nuestro punto de vista, hay datos que nos permiten pensar que los sustantivos de medida incluidos en ssNn que complementan a verbos están actualizados, esto es, son denotativos o referenciales, aunque esta denotación jamás se encuentra discriminada (orientada hacia grupos de entes particulares). La expresión de la medida y la referencia sí son compatibles en español, pero no la primera y la discriminación denotativa, incluso cuando esa expresión de la medida se lleva a cabo con ssnN cuyos sustantivos no son de medida.

No cabe duda de que, cuando decimos, por ejemplo, Gasol mide dos metros, dirigimos en el habla un signo del sistema de la lengua (metro) hacia una realidad extralingüística, en este caso, hacia un patrón de medida de la magnitud longitud: el trayecto recorrido en el vacío por la luz en un tiempo de 1/299.792.458 segundos. Con ello lo dotamos de una designación real, lo actualizamos. La expresión de la medida, además, exige siempre la de la cuantificación, pues aquélla lo que hace es establecer una relación entre una cantidad denominada magnitud y un determinado patrón adoptado al efecto (cf. Ferrater Mora 1982, pp. $2167-2168)^{14}$. No obstante, la designación real o denotación del sustantivo metro de nuestro ejemplo, aun a pesar de la cuantificación -Coseriu ob. cit., pp. 298-303 la caracteriza como una de las tres operaciones que, junto con la selección y la situación, abarca la discriminación-, no se encuentra discriminada, esto es, no se encuentra orientada hacia un ente particular o grupo de entes particulares al que se distingue de otros entes. La orientación de la denotación hacia un ente o grupo de entes particulares que conlleva la discriminación permite presentar los entes denotados como miembros discontinuos de un grupo o clase (dos niños) o como porciones de un objeto extenso, caso éste último de

${ }^{14}$ La cantidad se dice de lo que es divisible en dos o varios elementos integrantes, cada uno de los cuales es, por naturaleza, una cosa única y determinada. La cantidad puede ser discreta o continua (magnitud) y la magnitud no es sino una multiplicidad mensurable, esto es, una cantidad no discreta cuyas partes son continuas, pues confluyen en un límite común (cf. Aristóteles 1962, pp. 45-47, y 1970, pp. 264-266). Las magnitudes, si bien mayormente pertenecen al ámbito de la naturaleza (tiempo, longitud, latitud, superficie, volumen, masa/peso, temperatura, fuerza, intensidad, velocidad, presión...), también se encuentran en el ámbito de lo meramente cultural, caso del valor o precio. 
los nombres no contables (mucha agua) (cf. Coseriu, ob. cit., pp. 297298). En este sentido, por ejemplo, la denotación discriminada de los entes a los que hacen referencia los nombres de magnitudes sólo podrá presentarlos como porciones de un objeto extenso, pero nunca como miembros discontinuos de una clase - mucha/poca temperatura; *una/dos temperatura $(s)$-. Los nombres de patrones de medida, por su parte, designan objetos que ni se presentan como porciones de un objeto extenso (*poco/mucho metro), ni lo hacen como miembros de una clase. Es cierto que podemos decir dos/tres metros. Incluso, que los nombres de medida, al igual que otros que sí denotan miembros de una clase, pueden complementar introducidos por una preposición a un numeral colectivo (una decena de niños; una decena de metros), algo que no ocurre con los nombres que pueden designar porciones de objetos extensos (*una decena de aguas; *una decena de temperaturas). Sin embargo, en tanto que cuando decimos dos niños denotamos dos miembros diferentes de la clase niño, cuando decimos dos metros en mide dos metros no se denotan dos miembros distintos de una misma clase, sino la repetición de un mismo patrón de medida, que, como tal patrón, es único. La cuantificación de los nombres de medida sólo supone el número de veces que se alude a un mismo objeto de la realidad extralingüística, jamás la denotación de entes distintos de una misma clase. Si los nombres de medida tienen la capacidad de denotar sólo un objeto real (el patrón de medida de la magnitud correspondiente), resulta entonces imposible realizar discriminaciones (uno o un grupo frente a los demás) en esa denotación.

Los sustantivos que pueden denotar miembros diferentes de una misma clase, al tiempo que pueden discriminar la denotación, admiten que la discriminación sea bien una selección indefinida o particularizadora (en vi a unos pocos niños nos referimos a unos miembros de la clase niño, que pueden ser cualesquiera de ellos, frente a otros), bien una selección definida o individualizadora (en vi a los dos niños aludimos a unos miembros de la clase niño específicos frente a los otros). Los nombres de medida, desde el momento en que no pueden discriminar su denotación, carecen de estas opciones. Sin embargo, son posibles en español ejemplos como mide unos pocos metros, cuesta unos pocos euros, duró unos pocos meses o mide los dos metros, cuesta los dos euros, duró los dos meses. En los casos en los que artículo indefinido y cuantificación indefinida coinciden (mide unos pocos metros; cuesta unos pocos euros; duró unos pocos meses), artículo y cuantificador, debido a que los nombres de medida no designan clases, carecen de cualquier valor discriminador y se limitan a asignar un valor de inexactitud e imprecisión a la medición.

Con la combinatoria de artículo definido y cuantificación definida (mide los dos metros; cuesta los dos euros; duró los dos meses) caben, en principio, dos opciones: o se refuerza la definición de la medición o estamos ante una discriminación individualizadora de los sustantivos que no es 
denotativa, sino deíctica (señala elementos contextuales). En el primero de los casos, desde el momento en que no es posible la discriminación denotativa, lo que hace el artículo es incidir en la definición ya establecida por el cuantificador: se insiste en que se trata de dos metros, dos euros y dos meses, no de otras cantidades aproximadas y se presentan las cantidades medidas como cantidades de referencia que se muestran como un tope alcanzado en la medición, aunque sin cambio en el significado léxico del verbo. Es revelador en este sentido el comportamiento de estas estructuras en la negación. Si decimos Juan no mide dos metros, entendemos que Juan puede tener cualquier otra altura, inferior o superior. Ante Juan no mide los dos metros, se entiende que Juan posee una altura cercana a los dos metros, aunque sin sobrepasarla: dos metros queda como medida tope de referencia ${ }^{15}$. Por otra parte, si lo que se produce es una discriminación individualizadora deíctica, ocurre que, tanto con los ejemplos citados, como con otros con individualizadores distintos (mide esos dos metros; cuesta esos dos euros; duró esos dos meses), nos referimos a dos metros, dos euros y dos meses de los que ya se ha hablado.

No obstante, cuando se combinan artículo definido u otros individualizadores, como los demostrativos, y la cuantificación definida son posibles también, a la vez que la deixis, procesos metafóricos ${ }^{16}$. Hay sustantivos que no significan medida en la lengua y que, por consiguiente, no denotan patrones de medida que, mediante un uso metafórico, pueden aplicarse intencionalmente en el hablar para denotar medida ( pesa un templo, ejemplo de metonimia hiperbólica con el valor de «pesa los kilos que pesa un templo»). Con frecuencia en estos procesos metafóricos nos encontramos el hiperónimo de un sustantivo de medida (su hipónimo). Tal hiperónimo puede ser, incluso, el nombre de una magnitud duró mucho tiempo (= 'duró una cantidad de segundos, minutos, horas..., muy elevada'), cuesta mucho dinero (= 'cuesta una cantidad de euros, dólares..., muy elevada'). Igualmente, hay sustantivos que, al tiempo que significan medida en la lengua y designan patrones de medida, pueden también no significarla y no denotar patrón de medida alguno. Tal es el caso, por ejemplo, de euro y mes. El sustantivo euro designa bien un patrón de medida de la magnitud valor o precio (cuesta cuatro euros), bien los objetos reales que son las monedas de euro, designación que sí puede ser discriminada (los cuatro euros que lleva en el bolsillo se

\footnotetext{
${ }^{15}$ Para Sánchez López, ob. cit., p. 1116, n. 59, cuando el artículo definido introduce un complemento de medida, adquiere un valor gradativo que implica tácitamente una valoración de la cantidad como relativamente alta en la escala de lo esperable. Así, en el toro de Victorino Martín pesaba los seiscientos kilos; el de Domecq, en cambio, no pesaba los quinientos el artículo determinado señala la cantidad como extremo de una escala cuya orientación se ve afectada por la negación. Obviamente, ejemplos como pesó los quinientos kilos. Esperábamos los seiscientos y no pesó los quinientos kilos, aunque esperábamos menos no se corresponden con esta interpretación.

${ }^{16}$ Acerca de la metáfora entendida como la aplicación intencional en el hablar de un nombre para denotar lo que corresponde a la significación de otro, cf. Coseriu, ob. cit., p. 293, n. 22 y 1981, pp. 131-132.
} 
los di ayer). El sustantivo mes, a la vez que puede designar un patrón de medida de la magnitud tiempo (duró un mes), puede referirse también a periodos de tiempo concretos y, por consiguiente, discriminar su denotación (el mes de junio es caluroso). Pues bien, cabe la opción de usar metafóricamente este tipo de sustantivos para que realicen la denotación propia de cuando significan medida aun no significándola. Esto sucede fundamentalmente cuando aparecen complementando a verbos cuyo significado léxico exige la expresión de la medida. Así, en casos como estaré ausente mayo y junio; el congreso dura los/esos dos meses o me quedé sin los veinte euros que llevaba. La camisa me costó los/esos veinte euros, aun a pesar de los artículos, demostrativos y cuantificadores, no cabe hablar de una discriminación selectiva de las denotaciones de los sustantivos mes y euro. Artículos y demostrativos establecen aquí una discriminación individualizadora meramente deíctica. Ahora bien, las designaciones reales o denotaciones de los sustantivos mes y euro no son las de periodos concretos de tiempo y monedas, respectivamente, sino, debido a su combinatoria con verbos que exigen la expresión de la medida, las de cantidades de las magnitudes tiempo y precio equivalentes a la cantidad de tiempo que ocupan determinados periodos de tiempo concretos de un año y a la cantidad de precio (al valor) que se asigna a determinadas monedas de euro. Se aplican intencionalmente los sustantivos mes y euro sin la significación de medida para denotar lo que les corresponde cuando sí la significan ${ }^{17}$.

Cuando la combinación es del artículo indefinido con la cuantificación definida (mide unos dos metros; cuesta unos dos euros; duró unos dos meses) no resulta posible hablar de valor discriminador selectivo de artículo y cuantificador por el hecho de que en esta combinatoria el artículo indefinido no conlleva discriminación de la denotación de ningún sustantivo en español y dota a la cuantificación, numerable (asistieron unas mil personas) o mensurable (mide unos dos metros; cuesta unos dos euros; duró unos dos meses), de los valores de inexactitud e imprecisión, aunque menos que cuando artículo indefinido y cuantificación indefinida coinciden. Podríamos hablar ahora de cierto valor aproximativo (una cantidad de metros, euros o meses cercana, por encima o por debajo, a dos; una cantidad de personas cercana, por encima o por debajo, a mil). La combinatoria de artículo definido y cuantificación indefinida es, al igual que sucede con los sustantivos que no son de medida, agramatical, a no ser que el SN sea modificado por una oración de relativo que contribuya a la discriminación individualizadora - para los SSNN de medida siempre deíctica y nunca denotativa- que la disparidad semántica entre artículo

\footnotetext{
${ }^{17}$ Incluso, podríamos decir, por ejemplo, duró noviembre y diciembre, donde noviembre y diciembre, que tampoco denotan patrones de medida, pasan a designar lo que no es su designación habitual mediante la metáfora: una cantidad de tiempo equivalente a la que duraron dos periodos de tiempo concretos denominados noviembre y diciembre.
} 
y cuantificador (definición frente a indefinición) impide señalar (*mide los pocos metros; *cuesta los pocos euros; *dura los pocos meses; mide los pocos metros que suelen medir estos trastos/de los que te hablé; cuesta los pocos euros que suelen costar estos aparatos/que te dije; dura las pocas horas que suelen durar estos actos/que te advertí).

La discriminación y la expresión de la medida, por tanto, sólo son compatibles cuando aquélla es meramente deíctica (señala elementos contextuales) y no denotativa, sea con sustantivos de medida, como hemos visto, sea sin ellos (mide lo que yo te dije).

\section{LA COMPLEMENTACión DE LOS SUSTANTIVOS DE LOS COMPLEMENTOS DE MEDIDA}

Resulta lógico que los que no catalogan como referenciales los SSNN de medida se vean obligados a no aceptar la modificación de la denotación del sustantivo núcleo de estos sintagmas mediante cualquier tipo de complementación ${ }^{18}$. Ahora bien, identificar al mismo tiempo la referencialidad con la individualidad específica equivaldría a presentar ésta última como requisito sin el cual no es posible la restricción denotativa. Conforme a nuestro planteamiento, individualización y restricción son aspectos distintos, y sin ningún tipo de dependencia entre sí, de la determinación nominal. La individualización es un tipo de discriminación selectiva y, como tal, tiene que ver con el proceso de dirigir los signos virtuales del sistema de la lengua hacia la realidad no lingüística, pero no con el de modificar sus posibilidades designativas, con el que sí tiene que ver la restricción. Fue Coseriu 1989, pp. 305-306, el que presentó la restricción, para él especificación, como un tipo de delimitación nominal. Así, en tanto que la explicación acentúa una característica inherente de lo denotado (el vasto océano) y la especialización precisa los límites extensivos o intensivos dentro de los cuales se considera lo determinado, aunque desde un punto de vista interno, sin aislarlo ni oponerlo a otros determinables susceptibles de caber bajo la misma denominación (el sol matutino; los españoles como europeos) ${ }^{19}$, la especificación restringe «las posibilidades referenciales de un signo, añadiéndoles notas no-inherentes a su significado» (cf. Coseriu, ob. cit., p. 306) (castillo medieval). Por consiguiente, de la misma manera que es posible la individualización sin restricción (veo a un hombre), también lo es la restricción sin la individualización, fundamentalmente porque es posible la restricción

\footnotetext{
${ }^{18}$ En sentido contrario, Gràcia i Solé, ob. cit., p. 197, alude precisamente a la posibilidad de ser complementados que estos sustantivos tienen en catalán (el pernil pesova tres quilos ben bons; aquest llibre valia un duro d'abans de la guerra) para pensar en poder dotar de valor referencial a los sintagmas de medida.

${ }^{19}$ Tanto en el sol matutino como en los españoles como europeos se hace referencia a entidades (el sol, los españoles) teniendo en cuenta sólo uno de sus aspectos (el carácter matutino, la condición de europeos) y obviando otros.
} 
de la denotación de un sustantivo que, al tiempo, ha sufrido una discriminación particularizadora y no individualizadora. Es Bosque 1998, p. 67 el que propone Juan busca varios ayudantes competentes para negar que sea la naturaleza no específica de las frases de medida la causa de la imposibilidad de restringir mediante la determinación la denotación de los sustantivos que en ellas aparecen. Según este autor, ob. cit., p. 70, que no podamos determinar los sustantivos de medida se asocia al hecho de que tampoco se pueden restringir, lo que se debe, continúa, a que no son referenciales. Su no referencialidad se deduce ahora, no de su carácter no específico, sino de que carecen de extensión, esto es, no denotan tipos/clases de individuos o entidades ni están asociados con una variable de tipo predicativo (cf. también Enç 1991). No obstante, pensamos, hacer depender el carácter referencial de los sustantivos de su carácter extensivo supone obviar otras maneras distintas que las unidades nominales tienen de aludir a lo extralingüístico. En rigor, la propuesta de Bosque impediría catalogar como referenciales los nombres propios, que, precisamente, se caracterizan por designar individuos que no pertenecen a clase alguna (cf. Bosque 1999, pp. 5-6 y Fernández Leborans 1999), y los nombres no contables, que no denotan clases, sino objetos extensos. Por otro lado, señalar que los sustantivos de medida no pueden ser complementados porque carecen de la posibilidad de restringir su denotación implica aceptar que toda complementación nominal es únicamente restrictiva e incapaz de otras opciones de modificación referencial distintas de la restricción.

Según Bosque 1998, pp. 68-69, conforme a lo dicho por Pesetsky, ErteschikShir y Kroch, las preguntas negativas presuponen interpretaciones restrictivas de grupo y este tipo de preguntas no es posible con los sintagmas de medida, lo que demuestra la imposibilidad de la restricción en la denotación de sus sustantivos. Parte Bosque de la idea de que mientras en ¿qué lugares no viste en tu viaje?, qué lugares presupone la existencia de un conjunto de lugares en la mente de los interlocutores, eso no sucede cuando desaparece la negación (¿qué lugares viste en tu viaje?). Mediante la pregunta negativa, continúa Bosque, se solicita que se seleccione un subconjunto de ese conjunto implícito. La inexistencia de oraciones como ${ }_{\text {¿ }}$ cuántas horas no dura esta película de Spielberg?, es consecuencia de la imposibilidad de establecer subconjunto alguno.

Desde nuestro punto de vista, tanto la pregunta parcial negativa como la no negativa en los ejemplos de Bosque muestran una discriminación explícita de la denotación del sustantivo lugar, la cual, a su vez, presupone una restricción denotativa (los lugares con la característica no inherente de haber sido vistos en el viaje, en un caso, y los lugares que carecen de ella, en el otro). Que este sustantivo designe un conjunto extensional de entidades permite establecer oposiciones entre subtipos en un mismo tipo: el subconjunto de los lugares que se vieron -por los que se pregunta sin la negación- frente al de los que no se vieron -por los que se ha de preguntar negativamente-. En el caso de los sustantivos de medida, que no designan tipos de unidades, sino patrones 
únicos, y que, por consiguiente, no son discriminables ni restringibles en su denotación, resulta imposible establecer oposiciones entre subconjuntos, lo que impide cualquier tipo de pregunta discriminadora y restrictiva, sea negativa o no. Sólo cabe preguntar por el número de veces que se repite el patrón designado, pero no por un subconjunto con una característica determinada o sin ella. Del mismo modo que en ¿qué lugares no viste en tu viaje?, se presupone un conjunto de elementos -el de los lugares que se podían ver en el viaje-, del que los lugares que no se vieron puede ser un subconjunto, en ¿qué lugares viste en tu viaje?, se presupone el mismo conjunto, del que los lugares que sí se han visto puede ser, igualmente, un subconjunto. La única diferencia estriba en que en la pregunta negativa parece sobreentenderse un subconjunto de lugares que se vieron, mientras que en la no negativa no se presupone ni un subconjunto de lugares que no se vieron ni uno de los que sí fueron vistos: todos o ninguno podrían ser respuestas perfectamente esperables. En ambos casos es el discriminador qué el que orienta la denotación hacia determinados miembros de la clase «lugar», si bien no la modifica, aun cuando la restricción se presuponga. Ninguna construcción en la que el sustantivo denota un ente no discriminado admite la pregunta con qué (tampoco la complementación restrictiva). Así, por ejemplo, en el hombre es mortal no cabe preguntar ¿qué/cuál hombre es mortal? ya que, obviamente, no se trata de ningún hombre en particular, sino de un ente con carácter general (cf. Coseriu 1989, p. 297). Por lo mismo, no es posible el uso del interrogativo quécon valor discriminador en los complementos de medida $\left(^{*}\right.$ ¿quéeuros cuesta?). Estructuras como ¿qqué metros mide Gasol?, no son sino ejemplos de elipsis textuales -iqué (cantidad de) metros mide Gasol?-, que suponen una especie de proceso de conversión de lo que es una cantidad continua y, por tanto, mensurable en una cantidad discreta y numerable no iniciado en casos como el de ¿qué cantidad de euros cuesta?

Desde nuestro punto de vista, es cierto que los sustantivos de medida no designan tipos de unidades y que, por consiguiente, no podemos en este caso discriminar individualmente ni restringir denotación alguna. Ahora bien, eso no significa que carezcan de referencia y sean meros restrictores de cuantificadores, pues pueden actualizarse. Prueba de ello es, precisamente, que admiten modificar su denotación mediante la complementación, si bien esa modificación sólo puede ser de especialización, pero nunca restrictiva. La delimitación nominal de especialización limita la denotación de estos sustantivos sin establecer oposiciones entre miembros de una clase. Así, por ejemplo, al ser metro un sustantivo que designa un patrón de medida aplicable a aspectos distintos de la magnitud longitud (altura, profundidad, etc.) y que, además, tiene la capacidad de complementar verbos cuyo significado léxico no especifica magnitud alguna, puede recibir determinaciones que orienten la referencia hacia un aspecto concreto de lo denotado (mide/tiene dos metros de longitud/de altura). En metros de longitud/de altura el sustantivo metro no alude a una serie de entidades de la clase "metro" (las que sirven para medir la longitud/la altura) en oposición a otras entidades de la misma clase (las que no miden la longitud/la altura), sino a un patrón 
de medida, que es único, teniendo en cuenta uno de los aspectos de su denotación (su condición de patrón que mide la magnitud longitud o la dimensión altura) y obviando los demás. Las mismas delimitaciones denotativas de especialización podrían advertirse en tiene dos toneladas de peso (imposible si el significado léxico del verbo especifica ya la magnitud: el contenedor pesa dos toneladas *de peso), o en el cubo tiene un litro de capacidad.

Bosque 1999, p. 23, n. 32 ya advirtió de que los nombres de medida no sólo pueden admitir complementos que designan la cantidad medida (dos toneladas de garbanzos; un litro de alcohol), sino también otros que designan magnitud. En el caso de los nombres de distancia, establece que se usan más frecuentemente con complementos que designan magnitud (dos metros de altura) que con los que designan cantidad medida (dos metros de ladrillos) y la razón que ofrece es que, quizás, las disposiciones lineales de los objetos no se conceptúan habitualmente como grupos mensurables, lo que dejaría sin explicar los casos en los que el complemento que acompaña a estos sustantivos no alude a una realidad discreta, sino continua (dos metros de tela). Desde nuestro punto de vista, la aparición de un tipo u otro de complemento con sustantivos como metro tiene que ver con la designación real de estos sustantivos, que, no lo olvidemos, pueden denotar un patrón de medida, pero también pueden no hacerlo y denotar entidades. Dependiendo de esto, la determinación de sus complementos será también distinta. Cuando sustantivos como metro designan un patrón de medida sólo pueden ser complementados por estructuras preposicionales que designan magnitud y esto sucede, ya lo hemos dicho, porque sustantivos como éste designan unidades de medida aplicables a distintas dimensiones de la magnitud longitud y porque pueden complementar, a su vez, verbos cuyo significado léxico no especifica una magnitud o una dimensión en concreto. Tal complementación se produce con la intención de especializar la denotación de sustantivos como metro. Sin embargo, no sería posible la casa mide dos metros *de ladrillos, puesto que la cantidad medida ya estaría en el sujeto, y estructuras como tiene dos metros de ladrillos serían unas en las que metro no designaría patrón de medida, sino entidades. No obstante, en los pocos casos en español en los que la expresión de la medida está realizada por el sujeto encontramos ejemplos que pueden contradecir nuestra hipótesis, pues el sustantivo está complementado por una secuencia que no designa magnitud (en esta caja caben/entran dos metros de tela). Lo que hace la lengua, realmente, es, mediante la metáfora, emplear como designador de un patrón de medida de la magnitud volumen lo que habitualmente no denota tal patrón, sino una cantidad concreta y numerable que nada tiene que ver con esa magnitud (dos metros de tela). En casos como éstos, lo que en realidad se designa es que una caja ocupa una cantidad de espacio (metros cúbicos, litros, etc.) equivalente a la que ocupan dos metros de tela.

Por el contrario, cuando sustantivos como metro no designan patrón de medida, sino entidades, jamás pueden ser complementados por estructuras preposicionales que designan magnitud. En estos casos, estos sustantivos poseen una denotación que sí puede ser discriminada y restringida. Lo que hace de ladrillos en necesito dos metros de ladrillos es realizar una restricción en la denotación particularizada del sustantivo metro (unas entidades no específicas que son de ladrillos y no de otra cosa). En necesito esos dos metros de ladrillos, sin em- 
bargo, la restricción lo es en una denotación individualizada (unas entidades específicas que son de ladrillos y no de otra cosa) o en una individualización sólo deíctica (metros de ladrillos de los que ya se ha hablado).

Distintos de los casos en los que se especializa la denotación del sustantivo de medida son aquéllos en los que se modifica la referencia del SN de medida completo. Esa modificación puede ser ahora tanto de especialización como explicativa. Ejemplos de ambos tipos de modificación denotativa los encontramos en los que Bosque 1998, pp. 64-67, propone como excepciones solamente aparentes a su hipótesis acerca de la imposibilidad de la complementación restrictiva de los sustantivos de medida. Así, ante estructuras como sólo te costará mil insignificantes pesetas, este autor habla de adjetivos antepuestos, no restrictivos, que modifican el nombre como una aposición. No obstante, si bien es cierto que, tal y como señala Bosque, en el ejemplo no se alude a mil insignificantes monedas de una peseta, lo que descarta una interpretación individuativa, también lo es que no se expresa la repetición mil veces de un patrón de medida que tiene la característica inherente de ser insignificante. Desde nuestro punto de vista, si en dos metros de longitud/de altura el complemento preposicional determina sólo el sustantivo y el conjunto es cuantificado por el numeral, en mil insignificantes pesetas el numeral cuantifica el sustantivo de medida y el conjunto es determinado por el adjetivo: se alude a una cantidad (mil pesetas) de la que el hablante destaca una característica inherente, esto es, la de ser demasiado baja conforme al precio que debería tener lo que se compra.

La misma modificación referencial explicativa de todo el sintagma de medida la encontramos en casos en los que éste va acompañado por una oración de relativo. En duró dos horas que parecieron diez la oración de relativo, aun a pesar de no ir entre pausas, no restringe la denotación del sustantivo hora ampliando su intensión, pues éste carece de extensión. No se trata de dos miembros de la clase «hora» con la característica cada uno de parecer diez, sino de una cantidad (dos horas) sobre la que se aporta una información meramente adicional (parecer diez). Prueba de ello es que, a efectos de lo designado por dos horas, la oración de relativo es prescindible, lo que no sucede con las relativas con valor restrictivo (cf. Brucart 1999, p. 410) ${ }^{20}$.

Muestra de especialización referencial de la frase de medida completa la obtenemos en ejemplos en los que los sustantivos van con los

${ }^{20}$ El ejemplo contradice la idea de Bosque 1998, p. 67, de que, cuando los sintagmas de medida admiten oraciones de relativo, éstas están seleccionadas por el artículo determinado, al igual que ocurre con los nombres propios, cuya denotación no es restringible (la Barcelona que conocí). A la propuesta de Bosque sobre el nombre propio, idéntica a la de Kayne 1995, p. 103, Roca Urgell 1996, pp. 138 y 232-234, y Bianchi 1999, pp. 40-42, se opone la de Brucart, ob. cit., pp. 410-411, para quien este tipo de nombre en estos casos pierde su estatus y se convierte en nombre común, lo que permite la restricción denotativa de la oración de relativo. Nuestro punto de vista pasa por plantear que la oración de relativo modifica la denotación del nombre propio, aunque no restringiéndola, sino especializándola. 
denominados adjetivos epistémicos, no restrictivos y evaluadores de lo apropiado o lo desviado de una determinada medición (la huelga duró tres dias justos; el jamón pesa diez kilos exactos) o con los no restrictivos cuasicuantificativos (la película duró dos horas largas). En estos ejemplos no se habla, advierte acertadamente Bosque, de un tipo específico de días que tienen la cualidad de ser justos, de kilos que son exactos o de horas con más de sesenta minutos, sino de una huelga que duró exactamente tres días, de un jamón que pesa exactamente diez kilos y de una película que no duró exactamente dos horas, sino un poco más (cf. también Sánchez López, ob. cit., 1116, n. 59). No obstante, desde nuestro punto de vista, el hecho de que los patrones de medida puedan ser empleados en el ámbito de lo cotidiano sin la rigurosidad extrema exigible en ciertos ámbitos de conocimiento ha permitido que la lengua pueda hacer precisiones en la designación real de las frases de medida. Que en la vida diaria, en una especie de ampliación de sus denotaciones, apliquemos el nombre día a periodos de tiempo cercanos, pero distintos, de los de veinticuatro horas, el nombre kilo a porciones de peso parecidas, aunque diferentes, de las de mil gramos o el nombre hora a periodos de tiempo que no son de sesenta minutos, pero sí análogos, supone que pueda hablarse también de cantidades de horas, días o kilos con valor exacto, corto, escaso, largo, etc. En tres días justos y diez kilos exactos se hace referencia a un aspecto de la denotación de tres días y diez kilos -la alusión a periodos de tiempo que equivalen a 72 horas y a porciones de peso de 10.000 gramos, respectivamente- y se obvian otros, esto es, la designación de periodos de tiempo y porciones de peso aproximados a los anteriores que estas secuencias también pueden realizar. En dos horas largas la denotación de dos horas es la de un periodo de tiempo superior a 120 minutos y queda descartada la alusión a un periodo de 120 minutos exactos o a otros similares, pero inferiores. La existencia de esta delimitación denotativa de especialización es lo que distingue los ejemplos propuestos por Bosque de otros como la huelga duró justamente tres días, el jamón pesa exactamente diez kilos y la película duró un poco más de dos horas ${ }^{21}$. En casos como me costó mil pesetas de

${ }^{21}$ Si bien decir la película duró dos horas, cuando la realidad es que lo hizo un poco más o un poco menos, supondría un caso de lo que Sperber y Wilson 1986, pp. 231-237, denominan «loose talk», la especialización denotativa a la que aludimos (la película duró dos horas largas) supone lo contrario de cualquier ocultación de la verdad literal y el uso aproximado del lenguaje. En tanto que en el primer ejemplo la aproximación sí se establece entre lo que se dice y la realidad designada, en el segundo lo es sólo en el proceso extralingüístico de la medición.

El uso aproximado del lenguaje se encuentra igualmente en la falta de rigurosidad de las lenguas con las magnitudes físicas, que se manifiesta, por ejemplo, en casos como el del verbo pesar, al que se le suele acompañar con el nombre del patrón de medida propio de la magnitud masa. Desde el punto de vista de la Física, el peso no es sino la masa multiplicada por la aceleración de la gravedad y su unidad de medida es el newton. Sin embargo, se dice que Juan pesa setenta kilos.

Algo análogo sucede también en algunos casos con secuencias con el sustantivo vez que expresan medida y que modifican a otro tipo de unidades lingüísticas distintas del verbo. Así, por ejemplo, cuando decimos gana tres veces más/menos que Juan usamos la construcción con el 
las de antes la especialización denotativa de la frase completa estriba sólo en que se hace referencia a una cantidad teniendo en consideración su valor en épocas pasadas y obviando el del momento en que se habla.

Que la complementación nominal no es sólo restrictiva lo demuestra, pues, el hecho de que los sustantivos de medida, que carecen de extensión, puedan admitirla. Que los complementos que acompañan a estos sustantivos modifiquen su referencia prueba, a su vez, que éstos últimos poseen denotación. Ahora bien, esa modificación referencial, que habitualmente se lleva a cabo con complementos preposicionales que designan magnitud o dimensión, jamás con los que no lo hacen, sólo puede ser de especialización y nunca restrictiva o explicativa, pues estos sustantivos no designan conjuntos extensos de entidades y se refieren a patrones de medida perfectamente definidos que no necesitan explicación adicional alguna. Por otra parte, resulta indispensable distinguir la especialización de la denotación de los sustantivos de medida de otras posibilidades de modificación referencial de las frases de medida completas. Éstas últimas pueden ser tanto de especialización como explicativas, pero nunca restrictivas.

\section{TIPOS DE CONSTRUCGIONES Y VERBOS}

Quizás son tres los tipos de construcciones del español en las que aparecen los complementos verbales de medida no introducidos por preposición: 1) aquéllas en las que la cantidad medida se expresa en el sujeto. Lo que se mide es una magnitud que se relaciona con lo expresado en el sujeto: en Juan mide dos metros se expresa la medición de la altura de Juan; 2) aquéllas en las que la cantidad medida se expresa en el verbo. Lo que se mide es una magnitud que se relaciona con lo expresado en el verbo: en el agujero se agrandó dos metros no se mide la longitud del agujero, sino la del agrandamiento, y 3) aquéllas en las que la cantidad medida se expresa en un complemento verbal. Lo que se mide es una magnitud que se relaciona con lo expresado por otro complemento del verbo: en pagó cinco euros por la entrada se mide el precio de la entrada.

En el primero de los tipos encontramos verbos como albergar, alojar, arrastrar, cargar, coger (= medir), contener, costar, cumplir, desalojar, durar, hacer, llevar, levantar, medir, ocupar, pesar, soportar, tener, valer, etc. Se trata siempre de construcciones no activas en las que el sujeto sufre una ca-

valor de gana el triple/la tercera parte (un tercio) de lo que gana Juan. Si alguien gana realmente tres veces (el triple) de lo que gana otro, la formulación matemática no podría ser otra que $y=3 x$, pero, si alguien gana tres veces más que otro, la formulación debe ser $y=x+3 x$, donde $y$ sería el cuádruple de $x$, aunque la intención comunicativa de gana tres veces más que Juan sea la de expresar el triple. Igualmente, la formulación matemática que corresponde en rigor a gana tres veces menos que Juan es $y=x-3 x$, pero no $y=x / 3$, que es la que en el uso lingüístico se quiere expresar (cf. Serrano 2005). 
racterización que atiende a su mensurabilidad -jamás podrían ser respuesta a ¿qqué hace $X$ (= sujeto)?, pero sí a ¿qué le sucede a X (= sujeto)?-, lo que explica la imposibilidad de pasivas opuestas $(* d o s$ metros son medidos por Juan). Los complementos de medida siempre están regidos por estos verbos y eso los dota de un carácter argumental cuando aparecen junto a ellos. En el caso de que fuesen elididos en el discurso, siempre serían sobreentendidos por hablante y oyente. Ejemplos como esta maleta pesa (= es pesada) o la película dura (= tiene mucho metraje) no son sino muestras discursivas de la elisión de la proforma mucho sustituta de un complemento de medida. La argumentalidad de los complementos de medida con el tipo de verbos a los que hacemos referencia puede explicar el interés de la lengua por asemejarlos a otros argumentos: lo que en la realidad extralingüística no designa entes reales, sino patrones de medida, es concebido lingüísticamente como si de entes se tratara. Tanto es así que, en todos los casos, resulta aceptable la pronominalización acusativa (Juan mide dos metros; Juan los mide).

Entre los verbos de este primer apartado hay algunos que presentan una relación de homofonía con otros de distinto significado léxico. Son ejemplos de sincretismo léxico. Es el caso de pesar cuando expresa medida (el paquete pesa dos kilos) frente a pesar cuando significa medir el peso (Juan pesó el paquete). En tanto que el primero no admite construcción activa ni pasiva, el segundo sí lo hace (el paquete fue pesado por Juan). Idénticas características presentan albergar, alojar, arrastrar, cargar, coger, contener, desalojar, hacer, levantar, medir, ocupar, soportar, pero no costar, cumplir, durar, llevar, valer (cf. Sánchez López, ob. cit. p. 1118). Los que expresan una medición temporal o longitudinal y señalan cantidades que muestran una extensión en el tiempo o en el espacio, presentan, igualmente, una relación de homofonía con otros con un significado léxico diferente. Es el caso de coger, durar, llevar, medir, ocupar. Así, por ejemplo, frente al durar que expresa la medición del tiempo (la película duró dos horas) se encuentra otro durar que ya no indica medida alguna (la película duró desde las seis hasta las $o c h o)^{22}$. En tanto que en el primero el espacio de tiempo que se designa se presenta como una cantidad medida, en el segundo ese mismo espacio de tiempo ya no se presenta como tal cantidad medida, sino como un espacio de tiempo delimitado en su principio y fin ${ }^{23}$. Nos encontramos ante dos maneras distintas de concebir una misma realidad no lingüística que tiene su reflejo en la forma de cada una de las estructuras gramaticales: mientras que el durarque indica medida exige un complemento que puede ser sustituido por una forma pronominal en acusativo (la película dura dos horas; la pelicula las dura), lo que demuestra la concepción sustantiva

\footnotetext{
${ }^{22}$ Compárese con los verbos que no expresan una medición temporal o longitudinal - *la maleta pesa desde dos kilos a (hasta) tres kilos-

${ }^{23}$ Acerca de este tipo de conectores delimitativos cuando tienen valor temporal y del carácter durativo del predicado en estos casos, cf. García Fernández 1999, pp. 3193 y ss.
} 
de lo que en la realidad tiene carácter temporal, el durar delimitativo rige dos, cada uno con una proforma sustituta distinta con carácter temporal (la película duró desde las seis hasta las ocho; la película duró desde entonces hasta ahora), lo que demuestra la concepción lingüística temporal de lo que en la realidad, igualmente, tiene carácter temporal (cf. Devís Márquez 2000, pp. 127-129, n. 87). Que nos encontramos ante dos verbos diferentes y no ante dos posibilidades diatéticas distintas de un mismo verbo ${ }^{24}$ lo demuestra no sólo la existencia de dos significados léxicos desiguales (medición frente a delimitación temporal), sino también que el complemento que señala medida y los complementos delimitativos pueden aparecer juntos, aunque siempre separados por pausa, algo que no sucede jamás con complementos de posibilidades construccionales distintas de un mismo verbo: en tanto que, por ejemplo, no podemos simultanear el complemento agente y el objeto directo (*Juan pintó la casa, por Juan; *la casa fue pintada por Juan, la casa), sí son posibles estructuras como la película duró dos horas, de seis a ocho; la película duró de seis a ocho, dos horas. Obviamente, en el caso de éstas últimas, estamos ante construcciones elípticas en las que uno de los verbos durar está implícito (la película duró dos horas, (duró) de seis a ocho; la película duró de seis a ocho, (duró) dos horas) ${ }^{25}$. Cuando uno y otro durar aparecen con un sujeto que no muestra una cantidad mensurable o un espacio de tiempo delimitable solemos encontrarnos con metáforas de tipo metonímico (Juan (= la presencia de Juan) duró dos segundos/desde las dos hasta las tres en casa de sus padres).

Los verbos que expresan medida de la magnitud cultural precio, caso de costary valer, se caracterizan por no mantener ninguna de las relaciones de homofonía a las que hemos aludido (las naranjas cuestan/valen dos euros; *Juan cuesta/vale las naranjas). Una oración como Las naranjas cuestan/valen de (desde) ocho euros a (hasta) diez euros/de ocho a diez euros/entre ocho y diez euros continúa expresando medición (las naranjas cuestan/ valen una cantidad que se encuentra entre los ocho y los diez euros), pero no indica la delimitación de un espacio de la magnitud precio situado entre dos puntos concretos, sólo la cuantitativa. El caso de tener es especial, pues, aun a pesar de poder expresar la medida de la magnitud tiempo (este cuadro tiene dos siglos) y de la magnitud longitud (Juan tiene dos metros), no puede indicar ni la delimitación temporal (*este cuadro tiene desde 1800 a 2000) ni la delimitación longitudinal (*Juan tiene desde aqui hasta alli). En este sentido, cabe recordar el carácter excesivamente neutro de tener en lo que a la expresión de la medida se refiere: no sólo puede expresar la medición del tiempo y la longitud, sino también la de otras magnitudes como la superficie (la parcela tiene mil metros cuadrados),

\footnotetext{
${ }^{24}$ La idea es opuesta a la que se propone en Cano Aguilar 1999 acerca de la alternancia de objeto directo y régimen preposicional con un mismo verbo.

${ }^{25}$ En la película duró de dos a tres horas/entre dos y tres horas, a la vez que la medición temporal, hay una delimitación que sólo es cuantitativa, no de un espacio de tiempo.
} 
el peso (el paquete tiene dos kilos), etc. La misma variedad en cuanto a la expresión de la medición de magnitudes distintas presenta hacer (este depósito hace dos litros (volumen), todo esto hace cuarenta euros (precio), el púgil hizo noventa kilos en la báscula (peso), ayer hicimos veinticinco años de casados (tiempo)) y la misma imposibilidad en cuanto a la delimitación temporal (*ayer hicimos desde 1980 a 2005 de casados).

Con los verbos de este primer grupo -también con los de los siguientes- puede darse la expresión metafórica de la medida por parte de signos que no designan patrones de medida. En estos casos el hiperónimo suele aparecer en vez del hipónimo. Ese hiperónimo puede ser el nombre de una magnitud (me llevó mucho tiempo; tiene poca altura) o no serlo (costó mucho dinero), pero siempre es un sustantivo que denota un objeto extenso. De ahí que la cuantificación sea en estos casos indefinida. Cuando el hiperónimo aparece complementado por un sintagma de medida introducido por preposición, es el sustantivo de éste el que aparece cuantificado definida o indefinidamente y no el hiperónimo (tiene una profundidad de diez/muchos metros). La metáfora también puede darse mediante el cambio del patrón de medida (me costó dos horas encontrarlo; la charla duró dos kilómetros).

En el segundo tipo de construcciones (aquéllas en las que lo medido queda expresado por el verbo) encontramos el grupo de verbos de mayor extensión con diferencia. Quizás uno de los tipos más numerosos sea el de aquéllos que siempre admiten la alternancia entre un complemento temporal introducido por la preposición durante y otro, también temporal, pero no preposicional, los cuales dotan de un carácter atélico al suceso que se expresa (trabajó dos horas/durante dos horas). En la lista hay tanto verbos que aparecen en estructuras activas como verbos que jamás se encuentran en este tipo de construcciones (bailar, cantar, dormir, esperar, llover, quejarse, tener, trabajar, vivir). El complemento temporal no preposicional jamás tiene carácter regido. Su elisión no supone sobreentendimiento automático por parte de hablante y oyente. No obstante, con aquéllos que admiten estructuras transitivas y la elisión del objeto directo existe cierta tendencia a argumentalizar este tipo de complementos permitiendo su pronominalización acusativa (trabajó dos horas; las trabajó), pero no su conversión en sujeto de una estructura pasiva correspondiente $(*$ dos horas fueron trabajadas por alguien). Tal pronominalización no sucede cuando el objeto directo no está elidido (trabajó el barro dos horas; *las trabajó el barro), ni con los verbos que sólo se presentan en estructuras intransitivas (se estuvo quejando dos horas; * se las estuvo quejando). Todos estos verbos con posibilidad de un complemento de medida temporal atélico no preposicional admiten igualmente la construcción en la que no se expresa medición, sino delimitación temporal (bailó desde las seis hasta las ocho). La tendencia a la argumentalización mediante la pronominalización acusativa en los casos en los que es posible debería 
llevarnos a distinguir verbos homófonos, unos que rigen un complemento de medida temporal y otros que no rigen complemento temporal alguno, pero sí pueden facultativamente expresar la delimitación temporal (trabajar dos horas/trabajar desde las dos hasta las cuatro).

Verbos que también podrían ser incluidos en el grupo anterior en lo que a la expresión de la medida temporal se refiere, cabría agruparlos por separado atendiendo a su disponibilidad para expresar del mismo modo la medición de la magnitud longitud. Nos referimos a aquellos verbos que indican desplazamiento, caso de andar, ascender, avanzar, bajar, correr, escalar, recorrer, retroceder, etc. Todos aparecen siempre en estructuras activas (anduvo dos kilómetros), rigen el complemento de medida -que, si bien admite pronominalización acusativa (los anduvo), jamás se convierte en sujeto de una pasiva opuesta (*dos kilómetros fueron andados)- y mantienen una relación de homofonía con otros verbos con significado léxico diferente que no expresan medida, sino delimitación espacial mediante la rección de complementos con carácter ablativo, perlativo y adlativo (correr dos kilómetros/correr desde Cádiz por la playa hasta San Fernando).

Un tercer grupo de verbos en el segundo tipo general de construcciones con complementos de medida no preposicionales sería el de aquéllos que expresan la medición de magnitudes de distinta clase (longitud, tiempo, peso, precio...), pero que se caracterizan por hacerlo tanto en construcciones causativas en las que el sujeto le hace algo o le produce un efecto a alguien o algo (el viento aumentó dos metros el boquete) como en estructuras procesuales no agentivas (el boquete aumentó dos metros). Destacan aquí verbos como achicar, adelgazar, aumentar, bajar, disminuir, empequeñecer, encarecer, engordar, envejecer, menguar, prolongar, rebajar, reducir, rejuvenecer, subir, etc. (cf. Sánchez López, ob. cit., pp. 11191120). En las construcciones causativas el complemento de medida posee valor argumental, ya que el significado léxico de estos verbos exige la expresión de la medida, pero jamás puede sufrir pronominalización acusativa, pues siempre hay presente otro complemento verbal objeto directo (*el viento los aumentó el boquete). En el caso de las construcciones procesuales, el complemento de medida sigue estando regido, pero la posibilidad de pronominalización acusativa va a depender de si el verbo exige o rechaza la partícula se para expresar proceso. Si la exige, la pronominalización no es posible (el boquete se agrandó dos metros; *el boquete agrandó dos metros; *el boquete se los agrandó). Es lo que ocurre con achicar, agrandar, empequeñecer, encarecer, prolongar, rebajar ${ }^{26}$, reducir, etc. Si no la admite, entonces sí cabe la pronominalización (mi hermano adelgazó dos

\footnotetext{
${ }^{26}$ El caso de rebajar es especial, pues cuando el complemento de medida indica precio la construcción con se es posible, pero carece de valor procesual el gobierno rebajó el precio de la gasolina dos euros; el precio de la gasolina se rebajó dos euros ( = alguien indeterminado rebajó el precio de la gasolina dos euros), algo que no sucede cuando el complemento expresa la medición de otras magnitudes (la solución rebajó el alcohol dos grados; el alcohol se rebajó dos grados).
} 
kilos; *mi hermano se adelgazó dos kilos; mi hermano los adelgazó), aunque los complementos de medida no pueden convertirse nunca en sujetos de una construcción pasiva opuesta (*dos kilos fueron adelgazados por mi hermano). Sucede esto último con adelgazar, aumentar, bajar, disminuir, engordar, envejecer, menguar, rejuvenecer, subir..

Todos los verbos de este tercer grupo, cuando van acompañados de un complemento que alude a la medición de las magnitudes porcentaje y precio, muestran una alternancia de este último, que puede ser no preposicional y preposicional, tanto en la construcción causativa como en la procesual (el Consejo Universitario redujo un 40\%/ en un $40 \%$ el número de carreras; el número de carreras se redujo un 40\% / en un 40\%; la especulación encareció miles de euros/en miles de euros la vivienda; la vivienda se encareció miles de euros/en miles de euros).

Verbos como crecer y decrecer son análogos a los del tercer grupo en cuanto a la diversidad de magnitudes de las que expresan su medición, pero con la salvedad de que, aunque sí lo hacen en las procesuales no agentivas, jamás aparecen en construcciones causativas (el árbol ha crecido dos metros; *Juan creció el árbol dos metros). El complemento de medida es argumental y admite la pronominalización acusativa (la partícula se no es posible) (el árbol los ha crecido), si bien no puede convertirse en sujeto pasivo (*dos metros han sido crecidos por el árbol).

Echar y tardar son verbos que expresan la medida de la magnitud tiempo, aunque, frente a los del primer grupo, sólo aparecen en construcciones no activas y su complemento temporal no admite alternancia con otro introducido por durante y está siempre regido (echó dos horas en comer; tardó diez minutos en vestirse). Echar admite la pronominalización acusativa (las echó en comer), pero no tardar (*las tardó en vestirse). Un aspecto interesante es la capacidad de ambos verbos para, mediante proceso metafórico, ser acompañados por un complemento que mide la longitud echó dos kilómetros en comer (= echó en comer el tiempo que se tarda en recorrer dos kilómetros); tardó dos kilómetros en hablar (= tardó en hablar el tiempo que se tarda en recorrer dos kilómetros).

Otros tipos de verbos dentro del grupo de los que miden una cantidad que es expresada por el propio verbo son los que expresan la medición de la longitud, como distar (el taller dista dos kilómetros de mi casa; *el taller los dista de mi casa; el taller dista hora y media de mi casa), los que expresan endeudamiento, como adeudar o deber (le adeudan mil euros; le deben mil euros; se los adeudan; se los deben; *mil euros le son adeudados/debidos), los que indican marcación, caso de marcar, señalar, indicar o mostrar (la báscula marcó sesenta kilos; la báscula los marcó; *sesenta kilos fueron marcados por la báscula), etc. Todos se caracterizan por aparecer en construcciones no activas y por el valor argumental del complemento de medida, si bien no es posible en todos los casos su pronominalización acusativa. El verbo hacer vuelve a presentar variedad en cuanto a las magnitudes de las que 
expresa medida. Puede medir la longitud como los verbos de desplazamiento (hicimos dos kilómetros; los hicimos) o expresar la medición del tiempo tanto en construcciones con sujeto (el corredor hizo nueve segundos en los cien metros; *el corredor los hizo en los cien metros) -con un valor análogo al de tardar-, como en construcciones sin él (hace dos años que no le veo; los hace). Haber puede expresar la medición del tiempo (hay dos horas hasta Cádiz; las hay hasta Cádiz) y la de la longitud (hay dos kilómetros hasta Cádiz; los hay hasta Cádiz) ${ }^{27}$. Llevar, la del tiempo (llevan casados veinticinco años; *los llevan casados) ${ }^{28}$.

Que la intensidad de acciones, procesos y estados pueda ser mensurada conlleva que una enorme cantidad de verbos admitan complementos de medida. Ahora bien, en estos casos los complementos ni admiten pronominalización acusativa, ni tienen carácter argumental y muestran siempre una modificación en su denotación producto de un proceso metafórico, pues no existe un patrón de medida para cada caso particular (me quiere/come/bebe una barbaridad; me importa un pito).

Por último, en el ámbito de las construcciones en las que lo que se mide está expresado por un complemento del verbo, si bien el número de verbos no es tan amplio como en las estructuras anteriores, destacan los que señalan la medición de la magnitud precio, casos de cobrar (me cobraron cuatro euros por la entrada, con alternancias del tipo me cobraron la entrada a cuatro euros), llevar (= cobrar) (me llevaron treinta euros por este jersey) o pagar (pagué treinta euros por el jersey, con alternancias del tipo pagué el jersey a treinta euros) (cf. Sánchez López, ob. cit., p. 1119). No menos importantes son otros que aluden a magnitudes diferentes, como echar (le eché dos años/dos kilos), hacer (en la calle hace dos grados de temperatura) o haber (hay dos grados de temperatura en la calle; hay dos atmósferas de presión en esa habitación; hay dos metros de profundidad en la laguna). En todos los casos resulta evidente la pronominalización acusativa del complemento de medida y su carácter argumental.

\section{Conclusiones}

De manera escueta, nuestro trabajo puede resumirse del siguiente modo: 1) ninguno de los rasgos habitualmente empleados permite asignar a los complementos verbales de medida no preposicionales en

\footnotetext{
${ }^{27}$ Adviértase la compatibilidad en hay dos kilómetros (desde aquí) hasta Cádiz de la medición y la delimitación longitudinal frente a la incompatibilidad de la medición y la delimitación temporal con verbos del tipo durar (*duró dos horas desde la seis hasta las ocho), lo que nos llevó antes a distinguir entradas léxicas distintas, aunque homófonas. En casos como hay dos horas (desde Algeciras) hasta Cádiz la medición es temporal mientras que la delimitación no lo es.

${ }^{28}$ Distíngase este llevar del que mide la cantidad expresada por el sujeto (este trabajo me ha llevado dos años) y del auxiliar en perífrasis con valor resultativo (llevan cumplidos veinticinco años de casados, llevan recorridos dos kilómetros, los llevan).
} 
español una función sintáctica concreta. Y no sólo porque esos rasgos o no son privativos de estos complementos o no los poseen todos, sino también porque equivalen a marcas exclusivamente descriptivas de tipo intralingüístico que nada tienen que ver con el establecimiento de relaciones sintagmáticas entre constituyentes oracionales. En este sentido, estos complementos, tanto los argumentales como los no argumentales, tienen siempre en nuestra lengua una función sintáctica determinadora y en pocos casos conforman lo determinado. 2) resulta imprescindible desprenderse de conceptos restringidos de referencia que impidan descripciones adecuadas de los hechos lingüísticos: la clitización, si bien no es general, no es un fenómeno ajeno a este tipo de complementos en español. 3) los sustantivos de medida son denotativos o referenciales, aunque su referencia jamás se encuentra discriminada (orientada hacia grupos de entes particulares). La expresión de la medida y la referencia sí son compatibles en español, pero no la primera y la discriminación denotativa. La discriminación y la expresión de la medida sólo son compatibles cuando aquélla es meramente deíctica y no denotativa. 4) es preciso distinguir la modificación referencial de los sustantivos de medida de la que sufren las frases de medida completas. El hecho de que los sustantivos de medida tengan denotación permite que ésta pueda ser modificada mediante la complementación nominal. No obstante, desde el momento en que estos sustantivos carecen de extensión y designan patrones de medida perfectamente definidos, esa modificación jamás es restrictiva o explicativa, aunque sí de especialización. Frente a esto, la modificación referencial de los SSNN de medida puede ser tanto de especialización como explicativa, nunca restrictiva. 5) la diversidad de tipos de construcciones y de verbos que en español admiten complementos de medida no introducidos por preposición exige ampliar los datos que deben ser tenidos en cuenta en una gramática descriptiva del español en este caso y no restringir nuestra atención a aspectos meramente parciales o no pertinentes.

\section{REFERENCIAS BIBLIOGRÁFICAS}

Alarcos Llorach, E. (1994): Gramática de la lengua española, Madrid, Espasa Calpe.

Alcina Franch, J., y Blecua, J. M. (1975): Gramática española, Barcelona, Ariel.

Álvarez Martínez, M. A. (1987): «¿Aditamento o complementos circuntanciales?», In memoriam Inmaculada Corrales, vol. I, Estudios lingüísticos, Santa Cruz de Tenerife, Universidad de La Laguna, pp. 47-58.

Aristóteles (1962): Categorías, traducción de F. de P. Samaranch, Madrid, Aguilar.

— (1970): Metafísica, vol. I, edición trilingüe por V. García Yebra, Madrid, Gredos. 
Báez SAn José, V. (2002): Desde el hablar a la lengua. Prolegómenos a una teoría de la sintaxis y la semántica textual y oracional, Málaga, Ágora.

Bally, CH. (1965): Linguistique générale et linguistique française, $4^{\underline{a}}$ ed., Berna, Éditions Francke.

Bianchi, V. (1999): Consequences of antisymmetry. Headed relative clauses, Berlín, Mouton de Gruyter.

BosQue, I. (1989): Las categorías gramaticales, Madrid, Síntesis.

- (1998): «Sobre los complementos de medida», Estudios en honor del profesor Josse de Kock, Lovaina, Leuven University Press, pp. 57-73.

— (1999): «El nombre común», en Bosque, I., y Demonte, V. (dirs.), Gramática descriptiva del español, vol. 1, Madrid, Espasa, pp. 3-75.

BrucART, J. M. (1999): «La estructura del sintagma nominal: las oraciones de relativo", en Bosque, I., y Demonte, V. (dirs.), Gramática descriptiva del espanol, vol. 1, Madrid, Espasa, pp. 395-522.

- (2001): «Adición, sustracción y comparación: un análisis composicional de las construcciones aditivo-sustractivas del español», en F. Sánchez Miret (coord.) Actas del XII Congreso Internacional de Lingüistica y Filología Románica, vol. 1 pp. 11-60, Salamanca, Max Niemeyer Verlag. Accesible en http://seneca.uab.es/ggt/Reports/ GGT-02-4.pdf.

Cano Aguilar, R. (1981): Estructuras sintácticas transitivas en el español actual, Madrid, Gredos.

— (1999): «Los complementos de régimen verbal», en Bosque, I., y Demonte, V. (dirs.), Gramática descriptiva del español, vol. 2, Madrid, Espasa, pp. 18071854.

Cinque, G. (1990): Types of a-dependencies, Cambridge, The MIT Press.

Coseriu, E. (1981): «Introducción al estudio estructural del léxico», Principios de semántica estructural, $2^{\underline{a}}$ ed., versión española de M. Martínez Hernández, Madrid, Gredos, pp. 87-142.

- (1989b): «Determinación y entorno», Teoría del lenguaje y lingüística general, $3^{\text {a }}$ ed., Madrid, Gredos, pp. 282-323.

Cuartero Otal, J. (2003): Cosas que se hacen. Esquemas sintáctico-semánticos agentivos en español, Frankfurt am Main, Peter Lang.

Chомsкy, N. (1982): Lectures on goverment and binding, $2^{\underline{a}}$ ed., Dordrecht, Cinnaminson, Foris Publications.

Demonte, V. y Masullo, P. J. (1999): «La predicación: los complementos predicativos», en Bosque, I., y Demonte, V. (dirs.), Gramática descriptiva del espanol, vol. 2, Madrid, Espasa, pp. 2461-2523.

Devís Márquez, P. P. (2000): Fundamentos teóricos básicos de morfología y semántica oracionales, Málaga, Ágora.

— (2004): «Estructuras sintácticas y niveles lingüísticos», Verba 31, pp. 103-149.

- (2005): «Algunos problemas en la teoría de los esquemas oracionales», en Wotjak, G. y Cuartero Otal, J. (eds.), Entre semántica léxica, teoría del léxico y sintaxis, Frankfurt y Main, Peter Lang, pp. 357-372.

ENÇ, M. (1991): «The semantics of specificity», Linguistic Inquiry 22, 1, pp. 125.

Espinosa García, J. (1995-1996): «Objetos directos no prototípicos o periféricos: la cuantificación como función semántica oracional», Pragmalingüistica 3-4, pp. 311-328. 
- (1997): Estructuras sintácticas transitivas e intransitivas en español, Cádiz, Servicio de Publicaciones de la Universidad de Cádiz.

- (1998): «El suplemento en estructuras transitivas», en Rufino, G. (ed.), Atti del XXI Congresso Internazionale di Linguistica e Filología Romanza. Università di Palermo 18-24 settembre 1995, Tubinga, Max Niemeyer Verlag, pp. 273-282

Fernández lagunilla, M., y Anula Rebollo, A. (1995): Sintaxis y cognición. Introducción al conocimiento, el procesamiento y los déficits sintácticos, Madrid, Síntesis.

Fernández Leborans, M. J. (1999): «El nombre propio», en Bosque, I., y Demonte, V. (dirs.), Gramática descriptiva del español, vol. 1, Madrid, Espasa, pp. $77-128$.

Ferrater Mora, J. (1982): Diccionario de filosofía, 4⿳亠丷a ed., Madrid, Alianza Editorial.

García FernÁndez, L. (1999): «Los complementos adverbiales temporales. La subordinación temporal», en Bosque, I., y Demonte, V. (dir.), Gramática descriptiva del español, vol. 2, Madrid, Espasa, pp. 3129-3208.

Goldin Mark G. (1968): Spanish case and function, Washington D. C., Georgetown University Press.

Gràcia i Solé, Ll. (1989): La teoría temática, Bellaterra, Publicacions de la Universitat Autónoma de Barcelona.

Gutiérrez Ordóñez. S. (1997): «¿Hablamos del suplemento?», en La oración y sus funciones, Madrid, Arco Libros, pp. 175-194 (original en Scripta Philologica in memoriam Manuel Taboada Cid, I, La Coruña, Servicio de Publicaciones de la Universidad de La Coruña, 1996, pp. 433-451).

Happ, H. (1978): «Théorie de la valence et enseignement du français», Le français moderne 46, 2, pp. 97-134.

Kayne, R. S. (1995): The antisymmetry of syntax, Cambridge, Massachusetts, The MIT Press.

Leonetti Jungl, M. (1990): El artículo y la referencia, Madrid, Taurus.

Levin, B. (1993): English verb classes and alternations. A preliminary investigation, Chicago, The University of Chicago Press.

Lyons, J. (1981): Semantics, vol. I, Cambridge, Cambridge University Press.

Marcos Marín, F., Satorre Grau, F. J. y Viejo Sánchez, Ma a L. (1998): Gramática española, Madrid, Síntesis.

Mendívil Giró, J. L. (1994): «¿Expresiones referenciales inespecíficas o expresiones no referenciales?: Una aproximación gramatical a la independencia referencial», en Serra Alegre, E., y otros (eds.), Panorama de la investigació lingüistica a l'estat espanyol. Actes del I Congrés de Lingüistica General, Valencia, Universitat de València, pp. 100-111.

Pérez, Ma . R. (1989): «Consideraciones acerca de los complementos adverbiales», Verba 16, pp. 469-479.

Pesetsky, D. (1987): «Wh-in situ: movement and unselective binding», en Reuland, E. J. y Ter Meulen, A. G. B. (eds.), The representation of (in)definiteness, Cambridge, The MIT Press, pp. 98-129.

Porto Dapena, J. A. (1993): El complemento circunstancial, Madrid, Arco Libros.

RAE (1931): Gramática de la lengua española, Madrid, Espasa Calpe.

- (1983): Esbozo de una nueva gramática de la lengua española, Madrid, Espasa Calpe. 
Ramos, J. R. (1993): Introducció a la sintaxi, 2ae ed., Valencia, Tándem.

RızzI, L. (1990): Relativized minimality, Cambridge, The MIT Press.

Roca Pons, J. (1980): Introducción a la gramática, $5^{\underline{a}}$ ed., Barcelona, Teide.

Roca Urgell, F. (1996): La determinación y la modificación nominal, tesis doctoral, Departament de Filologia Espanyola, Facultat de Filosofia y Lletres, Universitat Autònoma de Barcelona (http://seneca.uab.es/ggt/Tesis/determinacion.pdf).

Rojo, G. (1985): "En torno a los complementos circunstanciales», en Lecciones del I y II curso de lingüística funcional, Oviedo, Universidad de Oviedo, pp. 181-191.

— (1990): «Sobre los complementos adverbiales», Profesor Francisco Marsá. Jornadas de Filología, Barcelona, Universitat de Barcelona, pp. 153-171.

SÁnchez López, C. (1999): "Los cuantificadores: clases de cuantificadores y estructuras cuantificativas», en Bosque, I., y Demonte, V. (dir.), Gramática descriptiva del español, vol. 1, Madrid, Espasa, pp. 1025-1128.

Serrano, S. (2005): «Cinco veces menos», El País, domingo 17 de julio de 2005, p. 15.

Smith, J. Ch. (1992): «Circumstantial complements and direct objects in the romance languages: configuration, case and thematic structure», thematic structure. Its role in the grammar, Dordrecht, Foris, pp. 293-316.

Sperber, D. y Wilson, D. (1986): Relevance: Communication and cognition, Oxford, Basil Blackwell. 